\title{
Effect of Vitamin-Containing Amino Acid Supplements on Menopausal Symptoms and Age- Related Skin Changes: A Randomised, Double-Blind, Placebo-Controlled Study
}

\author{
Rie Yamashita (D) - Masahiko Ooe - Yumiko Saya (D) - Natsumi Sugisawa • \\ Yumi Murakami (D) Hiroshi Matsunaka (D)
}

Received: June 21, 2021 / Accepted: August 5, 2021 / Published online: August 22, 2021

(C) The Author(s) 2021

\begin{abstract}
Introduction: Women aged $\geq 45$ years are known to experience various menopausal symptoms due to reduced oestrogen levels. Changes associated with cutaneous ageing, such as wrinkles and sagging, are also prominent in women in this age group. Numerous studies have evaluated the usefulness of individual basic nutrients and essential components, such as amino acids and vitamins, in menopausal women. The aim of this study was to comprehensively assess the effects of supplements containing amino acid and vitamin combinations on menopausal symptoms and age-related changes in the skin.

Methods: This is a randomised, placebo-controlled study on the effects of a supplement containing three types of amino acids [leucine, glutamine and arginine (LGA)] and 11 types of vitamins in 37 middle-aged women. The participants ingested either the test substance or a placebo twice daily for 8 consecutive weeks, at
\end{abstract}

R. Yamashita $(\bowtie)$

Shonan Fujisawa Plastic Surgery Clinic R, 571, Fujisawa, Fujisawa-shi, Kanagawa 251-0052, Japan e-mail: rielin2525@yahoo.co.jp

M. Ooe · Y. Saya · N. Sugisawa · Y. Murakami ·

H. Matsunaka

NOV Academic Research, TOKIWA Pharmaceutical Co., Ltd., 1-2-6, Minamiaoyama, Minato-ku, Tokyo 107-0062, Japan the end of which time the efficacy and safety of the test substance were assessed based on subjective symptoms of fatigue, Simplified Menopausal Index (SMI) score, the grade and number of wrinkles at the corners of the eyes, results of an analysis of the stratum corneum of the cheek and blood test results.

Results: None of the participants experienced adverse events, and all items assessed in our survey of subjective symptoms of fatigue showed a significant decrease in the test substance group (LGA group). Additionally, the SMI score of the LGA group was significantly lower than that of the placebo group. The LGA group showed significant improvement in the grade of the wrinkles in the corners of the eyes and the number of wrinkles, and the stratum corneum cell area declined significantly in the LGA group compared to the placebo group at the end of the study.

Conclusion: These results indicate that the vitamin-containing amino acid supplement improved menopausal symptoms and age-related changes in the skin (wrinkles).

Trial Registration: UMINO00029830.

Keywords: Menopausal Supplements; Amino acids; Leucine/ glutamine/arginine; Vitamins; Fatigue; Wrinkles; Age-related changes 


\section{Key Summary Points}

Why carry out this study?

Menopausal women experience a variety of symptoms affecting both their physical appearance and health due to decreased oestrogen levels.

Supplements containing amino acids and vitamins have been reported to have various benefits, but to date there have been no reports on their benefits in menopausal women.

We conducted a randomised, doubleblind, placebo-controlled study to investigate the usefulness of amino acid supplements for fatigue, menopausal symptoms and age-related skin changes caused by decreased levels of female hormones.

\section{What was learned from this study?}

We demonstrated that the vitamincontaining amino acid supplement used in this study can be safely ingested and can improve fatigue, menopausal symptoms and age-related skin changes caused by decreased levels of female hormones.

The vitamin-containing amino acid supplement tested can be expected to prevent menopause-associated health problems and the formation of wrinkles caused by ageing, as well as contribute to improved maintenance of beauty and health.

\section{INTRODUCTION}

Many women undergoing menopause experience a variety of symptoms and conditions, such as non-specific complaints and physical symptoms, such as fatigue and discomfort. The American Association of Clinical Endocrinology guidelines reported that $85 \%$ of women aged $\geq 50$ years experience some menopausal symptoms [1]. Menopausal disorders are defined as "pathologies among menopausal symptoms that interfere with daily life." Various physical, mental and psychological changes occur as a direct result of declining ovarian function. Treatments for menopausal symptoms include counselling, exercise therapy, hormone therapy, kanpo (traditional herbal medicine) therapy, psychotropic drug administration and nutritional therapy. However, there is no currently radical cure available for the management of menopausal symptoms. Over half of middle-aged and elderly women experience some form of distress with the appearance of wrinkles and sagging skin due to ageing [2]. Many of these women undergo treatments, such as laser treatment and other types of phototherapy, injections of hyaluronic acid or botulinum toxin, topical application of retinoid and ingestion of equol [3] and collagen peptide [4].

In the present study we focussed on the ability of basic nutrients and essential components, such as amino acids and vitamins, to improve symptoms unique to menopause. Amino acids are components of biological tissues and thus form a base upon which life is maintained, such as hormones, enzymes, antibodies and muscles. Leucine is an essential amino acid and has been reported to promote protein synthesis, improve muscles, improve exercise function, reduce muscle fatigue and improve liver functions [5, 6]. Glutamine acts as an energy substrate for the small intestinal mucosa and plays various roles in the immune system [7]. Arginine promotes circulation and lowers blood pressure $[8,9]$ and has also been reported to reduce exercise fatigue [10]. Vitamins are trace elements that are required for survival; however, since they cannot be biosynthesised within the body, insufficient amounts cause numerous deficiency-related diseases $[11,12]$.

These amino acids and vitamins can be expected to be beneficial in terms of improving several health problems and age-related skin changes that are caused by decreased levels of female hormones during and after menopause. 
Table 1 Amount of amino acids and vitamins in the test substance and the recommended daily amount

\begin{tabular}{lll}
\hline Amino acids and vitamins & $\begin{array}{l}\text { Amount of amino acids and } \\
\text { vitamins contained in the test } \\
\text { substance (1 packet) [unit:mg] }\end{array}$ & $\begin{array}{l}\text { Recommended daily } \\
\text { amount (women } \\
\text { aged 50-64 years) [unit:mg] }\end{array}$ \\
\hline Leucine & 900 & - \\
Glutamine & 450 & - \\
Arginine & 375 & - \\
Vitamin $\mathrm{A}$ & 0.45 & 0.7 \\
Vitamin $\mathrm{B}_{1}$ & 1.4 & 1.1 \\
Vitamin $\mathrm{B}_{2}$ & 1.6 & 1.2 \\
Vitamin $\mathrm{B}_{3}$ & 11 & 11 \\
Vitamin $\mathrm{B}_{5}$ & 5.5 & 5 \\
Vitamin $\mathrm{B}_{6}$ & 2 & 1.1 \\
Vitamin $\mathrm{B}_{9}$ & 0.4 & 0.24 \\
Vitamin $\mathrm{B}_{12}$ & 0.004 & 0.0024 \\
Vitamin $\mathrm{C}$ & 170 & 100 \\
Vitamin $\mathrm{D}$ & 0.005 & 0.0085 \\
Vitamin $\mathrm{E}$ & 8 & 6 \\
\hline
\end{tabular}

However, these issues have not yet been addressed. This study is the first to comprehensively evaluate the effects of supplements containing a combination of amino acids and vitamins on menopausal symptoms and agerelated changes in the skin. The aim of this study was to comprehensively investigate the usefulness of amino acid supplements for the management of fatigue, menopausal symptoms and age-related skin changes caused by decreased levels of female hormones. Additionally, we sought to prove that the intake of basic nutrients, such as, amino acids and vitamins, could contribute to the maintenance of beauty and health of menopausal women and thereby have a significant impact on women struggling with menopausal symptoms.

\section{METHODS}

\section{Participants}

Prior to the start of this study, we conducted a web-based investigation of the subjective symptoms of menopause (as defined by the Working Group for Occupational Fatigue of the Japan Society for Occupational Health) [13] and the Simplified Menopausal Index (SMI) [14] in women aged 40-59 years. Those selected as participants were women with total subjective symptom score $\geq 40$ and menopausal score $\geq$ 26 , indicating the need for caution in daily life activities, and "Wrinkle Grade", as defined by the Japanese Cosmetic Science Society [15], $\geq 3$ for wrinkles at the corners of the eyes. Women taking supplements and those were being treated for menopausal symptoms were excluded from the study. 


\section{Study Period and Participating Centres}

This study was conducted over a period of 8 weeks, between 18 October 2017 and 13 December 2017, at Shonan Kamakura General Hospital of the Okinawa Tokushukai Medical Corporation. The study was conducted in accordance with the Declaration of Helsinki and was approved by the Institutional Review Board of the Tokushukai Group. It was registered with the University Hospital Medical Information Network (UMIN) on 12 November 2017 (UMIN000029830). All participants were informed of the aims and methods of the study and gave their written consent.

\section{Test Substance}

The test substance was a single packet (3 g) containing three types of amino acids [L-leucine $900 \mathrm{mg}$ (L), L-glutamine $450 \mathrm{mg}$ (G), and Larginine $375 \mathrm{mg}(\mathrm{A})]$ and 11 types of vitamins $\left(\mathrm{A}, \mathrm{B}_{1}, \mathrm{~B}_{2}, \mathrm{~B}_{3}, \mathrm{~B}_{5}, \mathrm{~B}_{6}, \mathrm{~B}_{9}, \mathrm{~B}_{12}, \mathrm{C}, \mathrm{D}\right.$ and $\left.\mathrm{E}\right)$ contained in cornstarch powder (Table 1 ). The placebo consisted of $3 \mathrm{~g}$ of cornstarch powder. The test substance and the placebo were both packaged in an aluminium-laminated film; thus, they could not be distinguished based on their outward appearance.

\section{Study protocol}

A random number table was used to assign the participants to the test substance ingestion group (LGA group) and the placebo ingestion group (placebo group). The participants ingested one packet of either the test substance or placebo twice per day (morning and night) for a period of 8 consecutive weeks. During this period, the participants were instructed not to change their dietary patterns.

\section{Outcome Measures}

Physicians recorded the following data prior to the start of the study: participant's age, medical history, $\operatorname{drug}(\mathrm{s})$ that would be used in addition to the test substance or placebo during the study period (name of drug, method of administration, dose), concurrent treatments and skin findings. At the start and end of the study, the following items were assessed: subjective symptom survey for fatigue, SMI and wrinkle grade for wrinkles at the corners of the eyes. Additionally, the number of wrinkles at the corners of the eyes was assessed using replicas, the stratum corneum cell area at the cheeks was assessed using tape stripping and blood tests were conducted. During the test period, a telephone consultation desk was set up to identify adverse events, such as poor physical condition, caused by the test product. After each clinical examination, the attending physician asked and confirmed if the participants experienced any changes in their physical conditions during the examination. In cases wherein adverse events were observed, the details (severity classification, degree of severity, day discovered, treatment, date of outcome, outcome) and whether this study was the cause or not were recorded.

\section{Subjective Symptom Survey}

Fatigue status scores (sleepiness, anxiety, discomfort, listlessness, lack of mental clarity and total score) were assessed using a subjective symptom survey questionnaire.

\section{Simplified Menopausal Index}

We calculated the menopause index of the participants using the SMI questionnaire and used the total score in the analysis of the results. The SMI was used as a summary of climacteric complaints and consisted of the following ten items: four items of vasomotor nervous system symptoms (e.g. hot flashes over the face and excessive sweating, among others); four items of psychological/nervous system symptoms [e.g. poor sleep/light sleep and emotional volatility (quick to anger), among others]; and two other items, namely motor/nervous system symptoms (e.g. easy to tire, stiff shoulders/lower back pain/pain in limbs). Menopausal symptoms were evaluated on the basis of the strength of the symptoms as: strong/medium/weak/none. 


\section{Wrinkle Grade}

The wrinkles at the corners of both the left and right eyes were scored using an 8-step system in accordance with the wrinkle grade standard.

\section{Number of Wrinkles}

Impressions of the corners of each participant's eyes were obtained after they had washed their faces and rested calmly for $15 \mathrm{~min}$ at room temperature in a seated position. EXAFINE hydrophilic vinyl polysiloxane impression material (GC Corp., Tokyo, Japan) was used to make the impressions. The non-contact, threedimensional measuring device $\operatorname{PRIMOS}{ }^{\circledR}$ (Messtechnik GmbH, Teltow, Germany) was used to analyse the number of wrinkles that matched at the start and end of the study in an area on the impressions measuring $13 \times 18 \mathrm{~mm}$.

\section{Stratum Corneum Cell Area}

We obtained stratum corneum from the cheeks of the participants using tape stripping (CELLOTAPE $^{\mathrm{TM}} 24 \times 50 \mathrm{~mm}$; Nichiban Co., Ltd., Tokyo, Japan). We then calculated the cell area as the mean of ten cells based on microscopic images (BZ-8100E fluorescence microscope; Keyence, Osaka, Japan) images.

Table 2 Background of participants

\begin{tabular}{lll}
\hline Participant characteristics & $\begin{array}{l}\text { LGA } \\
\text { group }^{\mathbf{a}}\end{array}$ & $\begin{array}{l}\text { Placebo } \\
\text { group }\end{array}$ \\
\hline$n$ & 19 & 18 \\
$\begin{array}{l}\text { Mean age (years) } \\
\begin{array}{l}\text { Subjective symptom survey } \\
\quad \text { total score) }\end{array}\end{array}$ & $50.8 \pm 5.9 \pm 10.2$ & $50.7 \pm 4.2$ \\
$\begin{array}{l}\text { Simplified Menopausal Index } \\
\quad(S M I)\end{array}$ & $36.5 \pm 17.8$ & $44.3 \pm 20.4$ \\
\hline
\end{tabular}

Values in table are presented as the mean \pm standard deviation (SD)

${ }^{a}$ Group provided with the test substance that contained vitamins and three types of amino acids [leucine (L), glutamine $(\mathrm{G})$ and arginine $(\mathrm{A})$ ]

\section{Blood Tests}

Blood tests were performed to measure the levels of the following : glutamic-oxaloacetic transaminase, glutamic pyruvate transaminase, alkaline phosphatase (ALP), $\gamma$-glutamyl transpeptidase, lactate dehydrogenase (LDH), zinc turbidity test, urea nitrogen, creatinine, uric acid, amylase, total cholesterol, triglycerides, high-density lipoprotein cholesterol and C-reactive protein (CRP). Measurements were performed by the LSI Medience Corporation (Tokyo, Japan). CRP levels of $<0.01 \mathrm{mg} / \mathrm{dL}$ were taken as $0.01 \mathrm{mg} / \mathrm{dL}$ for the analysis.

\section{Statistical Analysis}

The data from both groups at the start and end of the study were compared using the Wilcoxon signed-rank test: subjective symptom survey, SMI, wrinkle grade, number of wrinkles, stratum corneum cell area and blood tests. Comparisons between the two groups were performed using the Mann-Whitney $U$ test. The differences were considered to be significant when the $p$ value was $<0.05$ in statistical analyses performed using IBM SPSS Statistics for Windows, version 27 ( SPSS IBM Corp., Armonk, N.Y., USA).

\section{RESULTS}

\section{Background of the Participant}

Of the 37 participants, 19 were randomised to the LGA group (mean age $50.8 \pm 5.9$ years) and 18 to the placebo group (mean age $50.7 \pm 4.2$ years) (Table 2 ).

\section{Adverse Events}

No adverse events were observed.

\section{Subjective Symptom Survey}

Comparison of the scores obtained at the start and end of the study showed that the scores for sleepiness, anxiety and discomfort separately and the total scores declined significantly in 


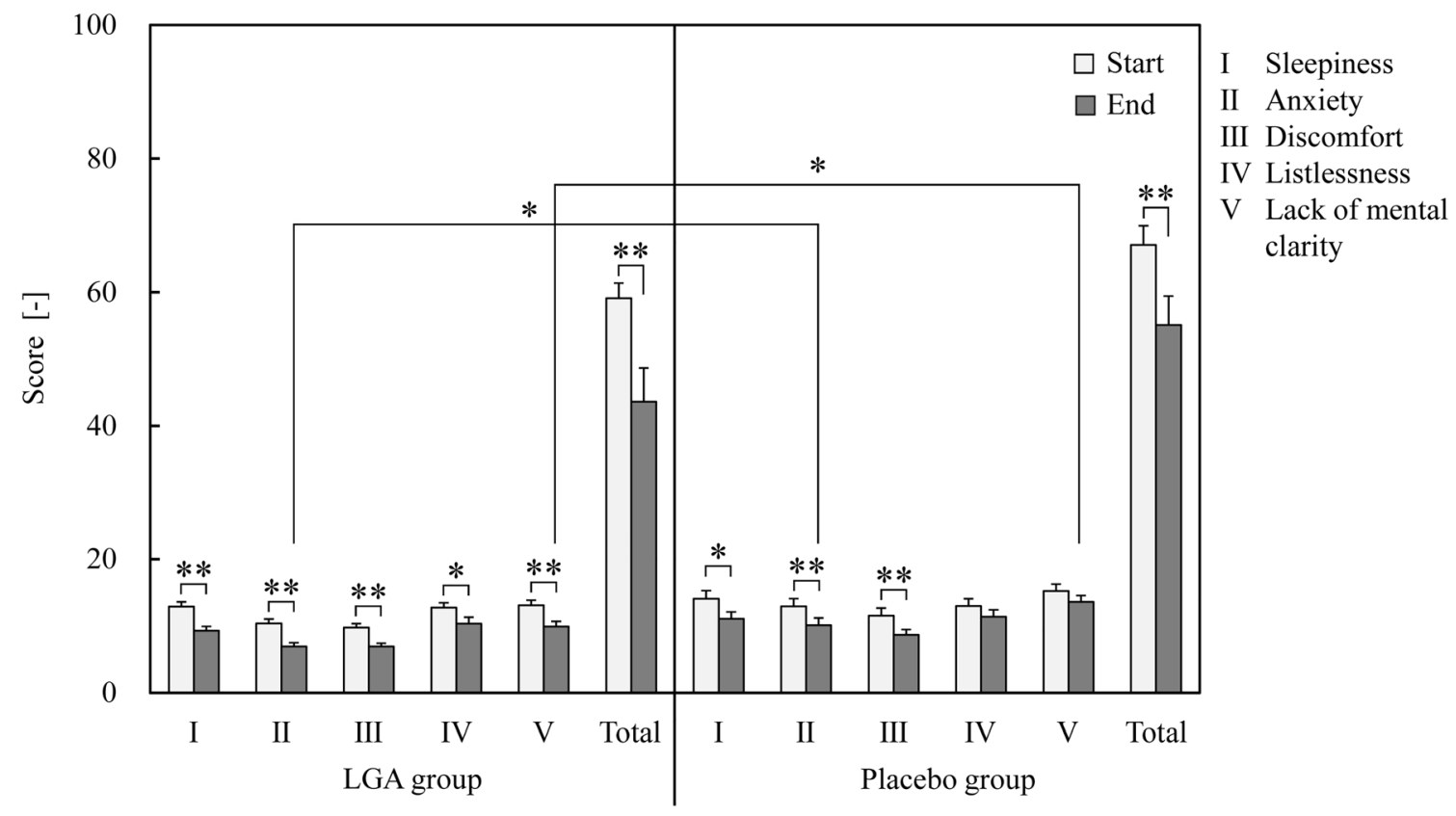

Fig. 1 Fatigue scores for separate items (drowsiness, anxiety, discomfort, drowsiness, lack of mental clarity) and total fatigue scores using subjective symptom survey in the LGA and placebo groups. Data are expressed as the mean \pm standard error of the mean (SEM) (LGA group: $n=19$; placebo group: $n=18$ ). The $p$ value was calculated using the Wilcoxon signed-rank test [scores at start of

both the LGA and placebo groups. Listlessness and lack of mental clarity declined significantly only in the LGA group. Comparison of the groups at the end of the study showed that the LGA group had significantly lower scores for anxiety and lack of mental clarity than the placebo group (Fig. 1).

\section{Simplified Menopausal Index}

The LGA group showed a decline from a score of $36.5 \pm 4.1$ at the start of the study to $29.6 \pm 3.7$ at the end of the study, while the placebo group showed an increase from a score of $44.3 \pm 4.8$ at the start of the study to $44.7 \pm 4.5$ at the end of the study. Although comparisons of menopausal indices obtained at the start and end of the study showed no statistically significant difference in either group, there was a significant difference in menopausal indices of the LGA study (START) vs. scores at end of study (END)] and the Mann-Whitney $U$ test (LGA group vs. placebo group). Asterisks indicate significant differences at ${ }^{*} p<0.05$ and ${ }^{* *} p<0.01$. LGA group received the test substance that contained vitamins and three types of amino acids [leucine $(\mathrm{L})$, glutamine $(\mathrm{G})$ and arginine $(\mathrm{A})]$

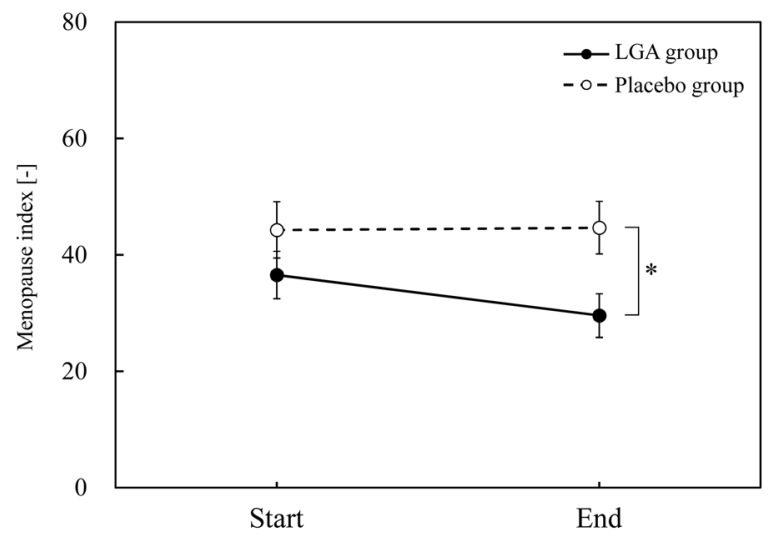

Fig. 2 Menopause index scores using the Simplified Menopausal Index (SMI) questionnaire in the LGA group and placebo group. Data are expressed as the mean \pm SEM (LGA group: $n=19$; placebo group: $n=18$ ). The $p$ value was calculated using the Wilcoxon signed-rank test [scores at start of study (START) vs. scores at end of study (END)] and the Mann-Whitney $U$ test (LGA group vs. placebo group). Asterisk indicates significant difference at ${ }^{*} p<0.05$ 


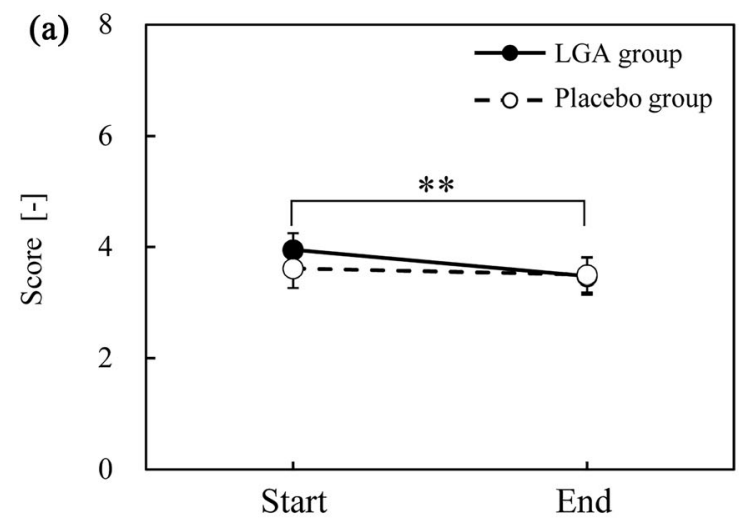

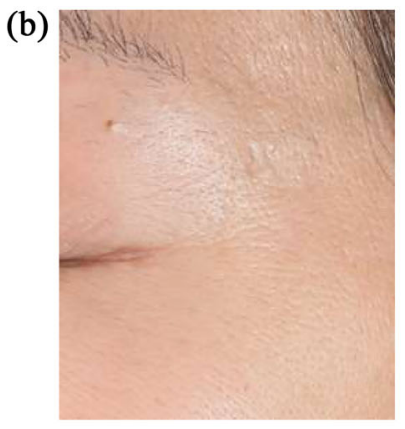

Start

Score 4

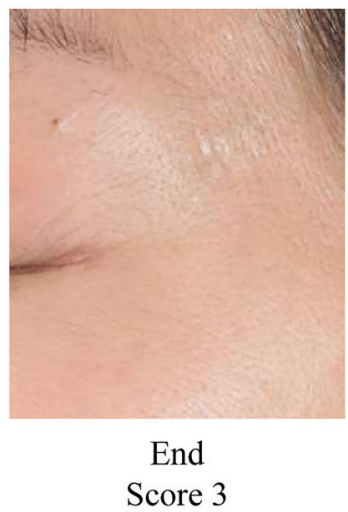

(c)

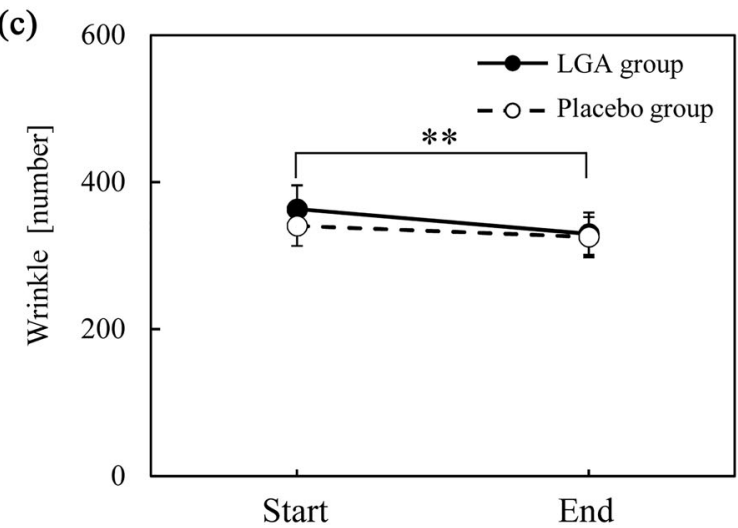

Fig. 3 a Wrinkle grade score at the corners of the eyes. $\mathbf{b}$ Typical case in the LGA group. c Number of wrinkles at the corners of the eyes. Data are presented as the mean \pm SEM (LGA group: $n=19$; placebo group: $n=18$ ). The $p$ value was calculated using the Wilcoxon signed-rank test [scores at start of study (START) vs. scores at end of study

and placebo groups at the end of the study (Fig. 2).

\section{Wrinkle Grade}

The wrinkle grade score for the corners of the eyes decreased significantly in the LGA group, from $3.95 \pm 0.30$ at the start of the study to $3.47 \pm 0.33$ at the end of the study. In contrast, there were no significant differences in the wrinkle grade score in the placebo group across the study period (Fig. 3a). Figure $3 \mathrm{~b}$ shows a typical case in the LGA group.
(END)] and the Mann-Whitney $U$ test (LGA group vs. placebo group). Asterisks indicate significant difference at ${ }^{* *} p<0.01$

\section{Number of Wrinkles}

The number of wrinkles at the corners of the eyes decreased significantly in the LGA group from $363.2 \pm 32.4$ wrinkles at the start of the study to $329.5 \pm 28.8$ at the end of the study. There were no significant differences in the number of wrinkles at the corners of the eyes in the placebo group across the study period (Fig. 3c).

\section{The Stratum Corneum Cell Area}

The size of the stratum corneum cell area in LGA group changed from $957.7 \pm 27.0 \mu \mathrm{m}^{2}$ at the start of the study to $905.8 \pm 22.8 \mu \mathrm{m}^{2}$ at the 


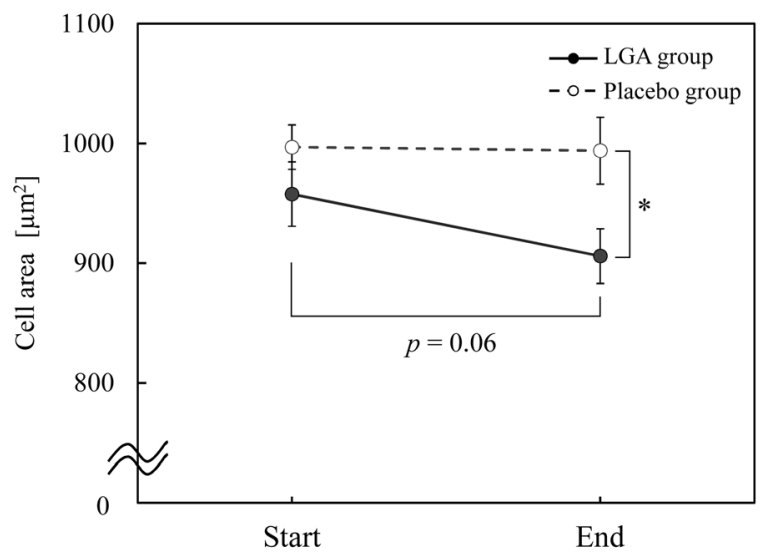

Fig. 4 Stratum corneum cell area of the cheeks in the LGA and placebo groups. Data are presented as the mean \pm SEM (LGA group: $n=19$; placebo group: $n=18)$. The $p$ value was calculated using the Wilcoxon signed-rank test [scores at start of study (START) vs. scores at end of study (END)] and the Mann-Whitney $U$ test (LGA group vs. placebo group). The asterisk indicates significant difference at ${ }^{*} p<0.05$

end of the study, indicating a declining trend $(p=0.06)$. At the end of the study, the cellular area was $905.8 \pm 22.8$ in the LGA group and $994.0 \pm 28.0$ in the placebo group, indicating that the LGA group had a significantly smaller stratum corneum cell area (Fig. 4).

\section{Blood Tests}

The results for all items in the blood tests revealed that no participant manifested health abnormalities at the end of the study. There was a significant difference in the levels of the items tested between the start and end of the study (Table 3). In the LGA group, the levels of ALP (start of study: $185.7 \pm 53.4$, end of study: $175.6 \pm 53.7), \mathrm{LDH}$ (start: $170.7 \pm 23.1$, end: $160.1 \pm 20.9$ ), and uric acid (start: $4.5 \pm 1.1$, end: $4.3 \pm 1.0$ ) showed significant decrease, while urea nitrogen (start: $11.2 \pm 3.1$, end: $13.1 \pm 2.8$ ) showed a significant increase. In the placebo group, total cholesterol (start: $208.6 \pm 25.5$, end: $218.1 \pm 33.1$ ) showed a significant increase. In addition, a comparison of all the items in the LGA group and the placebo group at the start and the end of the study showed that there were no significant differences.

\section{DISCUSSION}

We conducted a randomised, double-blind, placebo-controlled study that assessed the effectiveness of a supplement containing three types of amino acids (leucine, glutamine, and arginine) and 11 types of vitamins $\left(A, B_{1}, B_{2}, B_{3}\right.$, $\mathrm{B}_{5}, \mathrm{~B}_{6}, \mathrm{~B}_{9}, \mathrm{~B}_{12}, \mathrm{C}, \mathrm{D}$, and $\left.\mathrm{E}\right)$ on menopausal symptoms in 37 female participants.

Changes in fatigue status, as indicated by the results of the subjective symptom survey, showed that the separate scores for the items of sleepiness, anxiety, discomfort and the total score improved significantly in the LGA and placebo groups, indicating some degree of placebo effect. In contrast, listlessness and lack of mental clarity showed significant improvements only in the LGA group. We speculate that this is because arginine has a direct action on the urea cycle of the liver and promotes the excretion of ammonia, which is a fatigue substance [16] and that vitamin $B_{1}$ improved symptoms such as stiff shoulders, low back pain, lack of mental clarity and eye fatigue because it is a coenzyme of intracellular calorie metabolism and thereby facilitates nerve and muscle functions [17].

The SMI scores showed that there was no difference in either group between the start and end of the study, but that the LGA group had significantly lower menopausal scores at the end of the study than the placebo group. We speculate that this is due to the emotion-control effect associated with the synthesising effect of the vitamin B group on the neurotransmitters of the brain $[18,19]$; the suppressive effect of glutamine on excitement is associated with increased production of the intracerebral transmitter gamma-aminobutyric acid and its contribution to high-quality sleep [20].

Investigation of the wrinkle grade score for the corners of the eyes and the number of wrinkles indicated that the LGA group showed significant decline in wrinkle grade score and that there was a significant difference between the LGA group and the placebo group at the end 
Table 3 Blood test results

\begin{tabular}{|c|c|c|c|c|c|c|c|}
\hline \multirow[t]{2}{*}{ Blood test } & \multicolumn{3}{|c|}{ LGA group $(n=19)$} & \multicolumn{3}{|c|}{ Placebo group $(n=18)$} & \multirow{2}{*}{$\begin{array}{l}\text { Signficance level }(p) \text { of } \\
\text { Inter-group difference }\end{array}$} \\
\hline & Mean & SD & $p$ & Mean & SD & $p$ & \\
\hline \multicolumn{8}{|c|}{ Alkaline phosphatase (IU/mL) } \\
\hline Start & 187.5 & 53.4 & $0.019^{*}$ & 213.1 & 76.6 & 0.913 & 0.354 \\
\hline End & 175.6 & 53.7 & & 214.1 & 69.6 & & 0.078 \\
\hline \multicolumn{8}{|c|}{ Lactate dehydrogenase $(\mathrm{IU} / \mathrm{mL})$} \\
\hline Start & 170.7 & 23.1 & $0.005^{* *}$ & 172.0 & 25.5 & 0.061 & 0.952 \\
\hline End & 160.1 & 20.9 & & 165.9 & 23.6 & & 0.616 \\
\hline \multicolumn{8}{|c|}{ Urea nitrogen $(\mathrm{mg} / \mathrm{dl})$} \\
\hline Start & 11.2 & 3.1 & $0.007^{* *}$ & 11.6 & 3.0 & 0.828 & 0.693 \\
\hline End & 13.1 & 2.8 & & 11.8 & 2.4 & & 0.107 \\
\hline \multicolumn{8}{|c|}{ Uric acid $(\mathrm{mg} / \mathrm{dl})$} \\
\hline Start & 4.5 & 1.1 & $0.025^{*}$ & 4.5 & 0.9 & 0.816 & 0.988 \\
\hline End & 4.3 & 1.0 & & 4.4 & 0.8 & & 0.369 \\
\hline \multicolumn{8}{|c|}{ Total cholesterol $(\mathrm{mg} / \mathrm{dl})$} \\
\hline Start & 226.7 & 38.9 & 0.324 & 208.6 & 25.5 & $0.043^{*}$ & 0.101 \\
\hline End & 222.1 & 36.1 & & 218.1 & 33.1 & & 0.704 \\
\hline
\end{tabular}

Wilcoxon signed-rank test [start of study (Start) vs. end of study (End)]; Mann-Whitney $U$ test (LGA group vs. placebo group)

${ }^{*},{ }^{*}$ Significant difference at: ${ }^{*} p<0.05,{ }^{* *} p<0.01$

of the study in terms of the stratum corneum cell area. This decrease in wrinkle grade score in the LGA group is likely related the action of leucine in activating the mammalian target of rapamycin, which is involved in intracellular protein synthesis [21]. In addition, the stratum corneum cell area is known to increase due to slower turnover of the epidermis as a result of ageing [22]. The results of our study indicated that increased production of stratum corneum cells as a result of leucine improved epidermal turnover, which we believe reduced the cell area. As rationale for this belief, we noted that the evaluation of urea nitrogen level in blood tests showed a significant increase before and after the trial only in the LGA group. Increase in urea nitrogen levels signify the promotion of protein synthesis. Although previous studies of increased protein synthesis as a result of leucine supplementation have reported that there is a relationship with the muscles, our study is the first to report that it is associated with stratum corneum turnover. Previous studies have reported improvement of wrinkles by ingestion of equol and collagen peptide. In the study of equol intake [3], participants were divided into three groups: those who ingested $10 \mathrm{mg}$ of equol, $30 \mathrm{mg}$ of equol or a placebo, for 12 weeks. The results revealed a significant decrease in wrinkle area in the groups that ingested $10 \mathrm{mg}$ and $30 \mathrm{mg}$ of equol compared to the placebo group $(p<0.05)$. Furthermore, significant differences in wrinkle depth were noted between the group ingesting $30 \mathrm{mg}$ equol and the placebo group $(p<0.05)$ [3]. In the study of collagen peptide intake [4], participants were asked to consume either a beverage that included collagen peptides, vitamin $\mathrm{C}$ and vitamin $\mathrm{E}$ 
or to consume a placebo, for 12 weeks. The results of this showed that by week 9 of the study the wrinkle depth had significantly decreased by $8 \%$ in the collagen peptide intake group compared to the placebo group. However, no significant differences were observed after 12 weeks [4]. The results of the present trial showed significant decreases in the number of wrinkles before and after intake in the LGA group after 2 months, and no significant differences were observed in the placebo group. Each of the previous trials included 20-30 patients per group and they were double-blind, randomised, placebo-controlled clinical trials, with wrinkle improvement effects confirmed. However, the effects of the supplements could not be directly compared between studies due to different evaluation methods.

Our investigation of safety indicated that there were no significant changes in the blood tests or skin status, which indicates that ingestion of the test substance had no negative effects on health. We found that indices of liver and kidney function showed improvement in the LGA group, leading us to speculate that this improvement is due to factors such as the beneficial action of vitamin D on kidney failure [23] and the action of leucine in promoting the synthesis of albumin in the liver and production and secretion of hepatocyte growth factors [24]. Nevertheless, further detailed follow-up studies on the beneficial effects on liver and kidney function should be conducted in the future.

Similar to women in Japan, many women in the USA and European countries experience health problems during menopause and the appearence of wrinkles due to ageing of the skin. However, there is currently no established cure for these conditions. Since this study involved Japanese women, it is necessary to consider racial differences in future studies. As such, we see our study as a pilot study that evaluates the effects of supplements containing amino acids and vitamin combinations on menopausal symptoms and age-related skin changes. Our results suggest the possibility of preventing and improving various physical, mental and psychological changes resulting from decreased ovarian function in menopausal women through nutritional strategies. The basic nutritient intake of amino acids and vitamins has the potential to contribute to maintaining the beauty and health of menopausal women. In the future, we will provide more useful information for menopausal women by expanding the scale of the study, confirming the effectiveness of long-term intake of nutritional supplements and verifying the differences in effect in the stages of menopause (premenopausal, peri-menopausal, and post-menopausal). We may be able to provide basic nutrients.

\section{CONCLUSIONS}

Our results demonstrate that the test substance used in this study, a supplement containing amino acids and vitamins, can be safely ingested and that it can improve fatigue, menopausal symptoms and age-related skin changes caused by decreased levels of female hormones. Thus, when ingested by menopausal women, the test substance can be expected to prevent health problems of menopausal women and the formation of wrinkles caused by ageing, as well as contribute to improved maintenance of beauty and health.

\section{ACKNOWLEDGEMENTS}

We would like to thank the participants of the survey.

Funding. This study, the test substances and the journal's Rapid Service Fee were funded by Tokiwa Pharmaceutical Co., Ltd.

Authorship. All named authors meet the International Committee of Medical Journal Editors (ICMJE) criteria for authorship for this article, take responsibility for the integrity of the work as a whole, and have given their approval for this version to be published.

Author contributions. Rie Yamashita, Masahiko Ooe, Yumi Murakami and Hiroshi Matsunaka contributed to the conception and 
design of the study. Material preparation, data collection and analysis were performed by all authors. The first draft of the manuscript was written by Rie Yamashita, and Masahiko Ooe and all authors commented on previous versions of the manuscript. All authors read and approved the final manuscript.

Prior presentation. This manuscript has not been published or presented elsewhere in part or in entirety and is not under consideration by another journal.

Disclosures. Rie Yamashita declares no conflicts of interest associated with this manuscript. Masahiko Ooe, Yumiko Saya, Natsumi Sugisawa, Yumi Murakami and Hiroshi Matsunaka are employees of Tokiwa Pharmaceutical Co., Ltd.

Compliance with ethics guidelines. This study was conducted in accordance with the Declaration of Helsinki and was approved by the institutional review board of the Tokushukai Group. All participants were informed of the aims and methods of the study and gave their written consent.

Data availability. The datasets generated and/or analysed during the current study are available from the corresponding author on reasonable request.

Open Access. This article is licensed under a Creative Commons Attribution-NonCommercial 4.0 International License, which permits any non-commercial use, sharing, adaptation, distribution and reproduction in any medium or format, as long as you give appropriate credit to the original author(s) and the source, provide a link to the Creative Commons licence, and indicate if changes were made. The images or other third party material in this article are included in the article's Creative Commons licence, unless indicated otherwise in a credit line to the material. If material is not included in the article's Creative Commons licence and your intended use is not permitted by statutory regulation or exceeds the permitted use, you will need to obtain permission directly from the copyright holder. To view a copy of this licence, visit http://creativecommons.org/licenses/by$\mathrm{nc} / 4.0 /$.

\section{REFERENCES}

1. Goodman NF, Cobin RH, Ginzburg SB, Katz IA, Woode DE. American Association of Clinical Endocrinologists Medical Guidelines for Clinical Practice for the diagnosis and treatment of menopause. Endocr Pract. 2011;17(Suppl 6):1-25.

2. Ooe M, Seki T, Miura T, Takada A. Comparative evaluation of wrinkle treatments. Aesthetic Plast Surg. 2013;37:424-33.

3. Oyama A, Ueno T, Uchiyama S, et al. The effects of natural S-equol supplementation on skin aging in postmenopausal women: a pilot randomized placebo-controlled trial. Menopause. 2012;19:202-10.

4. Lupu MA, Gradisteanu Pircalabioru G, Chifiriuc MC, Albulescu R, Tanase C. Beneficial effects of food supplements based on hydrolyzed collagen for skin care (Review). Exp Ther Med. 2020;20:12-7.

5. Børsheim E, Bui QU, Tissier S, Kobayashi H, Ferrando AA, Wolfe RR. Effect of amino acid supplementation on muscle mass, strength and physical function in elderly. Clin Nutr. 2008;27:189-95.

6. Reule CA, Scholz C, Schoen C, Brown N, Siepelmeyer A, Alt WW. Reduced muscular fatigue after a 12-week leucine-rich amino acid supplementation combined with moderate training in elderly: a randomised, placebo-controlled, doubleblind trial. BMJ Open Sport Exerc Med. 2017;2: e000156.

7. Cruzat V, Rogero MM, Keane KN, Curi R, Newsholme P. Glutamine: metabolism and immune function, supplementation and clinical translation. Nutrients. 2018;10:1564.

8. Wennmalm A, Benthin G, Edlund A, et al. Metabolism and excretion of nitric oxide in humans. An experimental and clinical study. Circ Res. 1993;73: 1121-7.

9. Bai Y, Sun L, Yang T, Sun K, Chen J, Hui R. Increase in fasting vascular endothelial function after shortterm oral L-arginine is effective when baseline flowmediated dilation is low: a meta-analysis of randomized controlled trials. Am J Clin Nutr. 2009;89: 77-84.

10. Camic CL, Housh TJ, Zuniga JM, et al. Effects of arginine-based supplements on the physical 
working capacity at the fatigue threshold. J Strength Cond Res. 2010;24:1306-12.

11. Diab L, Krebs NF. Vitamin excess and deficiency. Pediatr Rev. 2018;39:161-79.

12. Heath ML, Sidbury R. Cutaneous manifestations of nutritional deficiency. Curr Opin Pediatr. 2006;18: 417-22.

13. Sasaki T, Matsumoto S. Actual conditions of work, fatigue and sleep in non-employed, home-based female information technology workers with preschool children. Ind Health. 2005;43:142-50.

14. Ikeda $H$, Inoue $T$, Uemura $S$, Kaibara $R$, Tanaka $H$, Node K. Effects of candesartan for middle-aged and elderly women with hypertension and menopausallike symptoms. Hypertens Res. 2006;29:1007-12.

15. Task Force Committee for Evaluation of Anti-Aging Function. Guideline for evaluation of anti-wrinkle products. J Jpn Cosmet Sci Soc. 2007;31:411-31.

16. Chen IF, Wu HJ, Chen CY, Chou KM, Chang CK. Branched-chain amino acids, arginine, citrulline alleviate central fatigue after 3 simulated matches in taekwondo athletes: a randomized controlled trial. J Int Soc Sports Nutr. 2016;13:28.

17. Bager P, Hvas CL, Rud CL, Dahlerup JF. Randomised clinical trial: high-dose oral thiamine versus placebo for chronic fatigue in patients with quiescent inflammatory bowel disease. Aliment Pharmacol Ther. 2021;53:79-86.

18. Almeida OP, Ford AH, Hirani V, et al. B vitamins to enhance treatment response to antidepressants in middle-aged and older adults: results from the B-VITAGE randomised, double-blind, placebo-controlled trial. Br J Psychiatry. 2014;205:450-7.

19. Sato K. Why is vitamin B6 effective in alleviating the symptoms of autism? Med Hypotheses. 2018;115:103-6.

20. Park S, Kang I, Edden RAE, Namgung E, Kim J, Kim J. Shorter sleep duration is associated with lower GABA levels in the anterior cingulate cortex. Sleep Med. 2020;71:1-7.

21. Duan Y, Li F, Li Y, et al. The role of leucine and its metabolites in protein and energy metabolism. Amino Acids. 2016;48:41-51.

22. Kawai M, Imokawa G, Mizoguchi M. Physiological analysis of the facial skin by corneocyte morphology and stratum corneum turnover. Nihon Hifuka Gakkai Zasshi. 1989;99:999-1006.

23. Armas LAG, Heaney RP. Vitamin D: the iceberg nutrient. J Ren Nutr. 2011;21:134-9.

24. Tomiya $\mathrm{T}$, Inoue $\mathrm{Y}$, Yanase $\mathrm{M}$, et al. Treatment with leucine stimulates the production of hepatocyte growth factor in vivo. Biochem Biophys Res Commun. 2004;322:772-7. 